\title{
Evaluating the effect of potassium on cellulose pyrolysis reaction kinetics
}

\author{
Anna Trendewicz ${ }^{\mathrm{a}}$, Robert Evans ${ }^{\mathrm{a}, \mathrm{b}}$, Abhijit Dutta ${ }^{\mathrm{b}}$, Robert Sykes ${ }^{\mathrm{b}}$, Daniel \\ Carpenter $^{\mathrm{b}}$, Robert Braun ${ }^{\mathrm{a}, *}$ \\ ${ }^{a}$ Colorado School of Mines, 1500 Illinois Street, Golden, CO, USA \\ ${ }^{b}$ National Renewable Energy Laboratory, 15013 Denver West Pkwy, Golden, CO USA
}

\begin{abstract}
This paper proposes modifications to an existing cellulose pyrolysis mechanism in order to include the effect of potassium on product yields and composition. The changes in activation energies and pre-exponential factors due to potassium were evaluated based on the experimental data collected from pyrolysis of cellulose samples treated with different levels of potassium (0-1\% mass fraction). The experiments were performed in a pyrolysis reactor coupled to a molecular beam mass spectrometer (MBMS). Principal component analysis (PCA) performed on the collected data revealed that cellulose pyrolysis products could be divided into two groups: anhydrosugars and other fragmentation products (hydroxyacetaldehyde, 5-hydroxymethyl furfural, acetyl compounds). Multivariate curve resolution (MCR) was used to extract the time resolved concentration score profiles of principal components. Kinetic tests revealed that potassium apparently inhibits the formation of anhydrosugars and catalyzes char formation. Therefore, the oil yield
\end{abstract}

\footnotetext{
*Corresponding author

Email address: rbraun@mines.edu (Robert Braun )
} 
predicted at $500^{\circ} \mathrm{C}$ decreased from $87.9 \%$ from cellulose to $54.0 \%$ from cellulose with $0.5 \%$ mass fraction potassium treatment. The decrease in oil yield was accompanied by increased yield of char and gases produced via a catalyzed dehydration reaction. The predicted char and gas yield from cellulose were $3.7 \%$ and $8.4 \%$, respectively. Introducing $0.5 \%$ mass fraction potassium treatment resulted in an increase of char yield to $12.1 \%$ and gas yield to $33.9 \%$. The validation of the cellulose pyrolysis mechanism with experimental data from a fluidized-bed reactor, after this correction for potassium, showed good agreement with our results, with differences in product yields of up to $5 \%$.

Keywords: cellulose, pyrolysis, potassium, kinetics, MBMS

\section{Introduction}

Biomass fast pyrolysis is a promising pathway for producing liquid fuels

3 from a variety of solid biomass feedstocks $[1,2,3]$. In order to accelerate the 4 development and commercialization of fast pyrolysis systems, it is impor5 tant to be able to predict product yields and composition. Having a better

estimate of biomass fast pyrolysis products allows more accurate technoeconomic assessment of potential conversion processes. Therefore, biomass pyrolysis reactor modeling has been the subject of multiple studies $[4,5,6,7,8]$

- However, modeling biomass fast pyrolysis is a challenging task because the reaction mechanism and the effects of feedstock composition on product yields are still not well understood.

Biomass composition and the amount of alkali metals present within its structure vary greatly depending on the environment of individual plants, 
however, some general characteristics might be distinguished. The major inorganic elements found in biomass are sodium, potassium, magnesium and calcium [9]. They mostly $(>90 \%)$ exist in water soluble or ion exchangeable forms [10]. The mass fraction of inorganic compounds is typically obtained from ash analysis because it is difficult to directly determine the weight fraction of alkali metals in raw biomass. Ash content is typically low for woody biomass $(<0.5 \%)$ and increases for herbaceous species and organic waste (up to $30 \%$ ash) [9, 11]. For reference, the main constituents of ash typical of pine, oak and switchgrass feedstocks were measured via ICP-MS analysis of the ashed samples and are presented in Table 1. [Table 1 here]The mass fraction of ash in woody feedstocks is relatively low $(0.3-0.4 \%)$ compared to grassy feedstocks $(\sim 6.0 \%)$. The major components of the ash are silica, potassium and calcium. An extensive study of the ash compositions from 86 biomass samples grouped into woody biomass, herbaceous and agricultural biomass, animal biomass, mixed biomass and contaminated biomass performed by Vassilev et al., [11] shows that the ash content and its chemical composition can vary over a wide range even for the same biomass type due to the dependence on plant origin and environment.

The effect of alkali/alkaline earth metals on biomass pyrolysis has been investigated by several researchers $[9,12,13,14,15,16]$. Scott et al., [12] first observed that alkali metals cause reductions in oil yield. Varhegyi et al., [13] investigated the effect of magnesium, sodium, iron and zinc on cellulose and biomass pyrolysis. He observed that magnesium did not change the overall weight loss characteristics or the formation of water and carbon dioxide. However, the yields of minor organic compounds (aldehydes, ketones, 
etc.) were significantly lower. Sodium was found to increase the yields of char, water, carbon dioxide and carbon monoxide at the expense of the oil yield. Iron and zinc were found to promote water and char formation.These results were confirmed by Shimada et al. [17] who also found that potassium chloride and sodium chloride cause a reduced levoglucosan yield and increased yields of water, carbon monoxide and char. Calcium chloride and magnesium chloride were found to lower the pyrolysis onset temperature and have a large effect on the product composition. Patwardhan et al., [9] provided more details about the alterations in product composition caused by potassium and sodium, which cause a severe reduction of the levoglucosan yield and increased yield of formic acid, glycolaldehyde and acetol. They also found that calcium and magnesium had a much weaker effect on the levoglucosan yield and negligible effect on the yields of formic acid, glycolaldehyde or acetol [9]. Despite these studies the underlying kinetic mechanism causing the observed changes in product yields is still not well understood.

Some researchers have suggested that the catalytic cellulose pyrolysis mechanism might be either acidic or alkaline [18, 19]. According to this theory, acid catalysts promote dehydration reactions, thus causing increased formation of levoglucosenone, various furan derivatives and char. Alkaline catalysts promote fission and disproportiation reactions, causing increased formation of glyoxal, acetaldehyde, carbonyl compounds and char. However, it has been shown that neutral salts also caused reduced levoglucosan yield and increased char yield $[20,21]$. Therefore, it was concluded that the catalytic mechanism was ionic and that alkalinity, acidity or neutrality was of secondary importance [15]. Piskorz et al., [22] found that levoglucosan for- 
mation and aldehydes formation during cellulose pyrolysis were competing reactions. The temperature had a weak influence on promoting either of the pathways and it has been concluded that metals determined the product composition [16]. It was suggested that metal cations might inhibit levoglucosan formation by capping the free ends of cellulose chain and thus preventing the unzipping reactions from proceeding. Kawamoto et al. [23] investigated the pyrolytic behavior of levoglucosan and they found that it can undergo secondary decomposition in the presence of other cellulose pyrolysis products. There are several possible pathways for the secondary levoglucosan reactions such as fragmentation into low molecular weight species or polymerization into polysaccharides, which are subsequently converted to solid carbonized products [24]. It is also possible for the secondary reactions to occur in a liquid phase[25]. Williams and Horne [15] found that the weight loss curves recorded during cellulose pyrolysis in the presence of salts were characterized by several distinct slopes. As a result, several activation energies for different temperature zones were reported, however the kinetic mechanism of cellulose pyrolysis in the presence of alkali was not explained [15]. The findings on the catalytic effect of alkali metals on the cellulose pyrolysis mechanism are summarized in Table 2. [Table 2 here]

Despite the lack of an established mechanism, the general observations are that inorganic compounds promote water and char formation and therefore, cause a reduced oil yield $[9,13]$. Moreover, the composition of pyrolysis oil is altered; the yield of levoglucosan decreases and the yield of glycolaldehyde, formic acid and acetol increase with an increased amount of salts [13]. However, it is not clear whether the observed changes in pyrolysis products 
are due to alterations in primary reaction pathways, promotion of secondary cracking reactions or a combination of both.

Most currently available cellulose and biomass pyrolysis reaction mechanisms $[26,27,28]$ do not capture the effect of inorganic compounds present in the biomass feedstocks on the pyrolysis products because of poor understanding of this phenomenon and the lack of appropriate experimental data. The first adaptation of a biomass pyrolysis reaction mechanism to account for the catalytic effect of alkali was the incorporation of secondary cracking reactions [29]. This adaptation is however only applicable when biomass particles are sufficiently large $(1 \mathrm{~cm})$. Therefore, there is still a need to develop an experimental procedure and a data analysis methodology applicable to smaller biomass particles that will allow to include the changes in kinetic parameters in the reaction mechanism. The goal of this work is to initiate this process by evaluating the effect of potassium on cellulose pyrolysis kinetics and incorporating the results into the cellulose pyrolysis reaction mechanism [28]. Potassium could potentially serve as an engineering approximation for all alkali metals due to its strong influence on levoglucosan and hydroxyacetaldehyde formation [14, 16], and its relatively large mass fraction in the biomass structure compared to other metals, as shown in Table 1. This paper explores the changes in reaction kinetics (reaction order, rate constants, activation energy) and product yields by analyzing the experimental data collected with a molecular beam mass spectrometer (MBMS) using statistical tools (principal component analysis and multivariate curve resolution) [30]. The results are incorporated into an existing reaction mechanism [28] and validated with experimental data [31] from a fluidized-bed reactor at the 
National Renewable Energy Laboratory (NREL).

\section{Experimental}

Experiments were performed with microcrystalline cellulose (Avicel) purchased from Sigma Aldrich and cellulose treated with different levels of potassium as $\mathrm{K}_{2} \mathrm{CO}_{3}$ (between $0.01 \%$ and $1 \%$ ). This corresponds to molar concentrations of potassium carbonate salt between 0.0013 and $0.13 \mathrm{mmol}$ $\mathrm{K}_{2} \mathrm{CO}_{3}$ /gram of cellulose. Previous work [30] has shown that the qualitative changes in cellulose-derived pyrolysis products, which approximate that found in biomass, could be affected by the addition of potassium carbonate at concentrations of potassium that are found in woody biomass. Additions of potassium as the chloride salt were not as effective in decreasing the levoglucosan yield in favor of hydroxyacetaldehyde. The alkaline nature of the carbonate salt may be an important part of the observed effect and a better approximation of what is observed in biomass. Cellulose samples were prepared by impregnating pure cellulose with aqueous solutions of potassium carbonate. The created slurry was then dried in air at room temperature. In order to ensure complete moisture removal, the samples were also dried in a furnace at $120^{\circ} \mathrm{C}$ for 6 hours before the experiment. The sample weight was $4 \mathrm{mg}$, which was a minimum weight required for the equipment to obtain an acceptable signal-to-noise ratio. Samples were pyrolyzed at five temperatures: $480^{\circ} \mathrm{C}, 490^{\circ} \mathrm{C}, 500^{\circ} \mathrm{C}, 510^{\circ} \mathrm{C}$ and $520^{\circ} \mathrm{C}$ in order to build a database for evaluating the reaction rate constant. The experiments were performed in a Frontier Laboratories 2020iD pyrolyzer (Fukushima, Japan) with an autosampler connected to the MBMS device, shown in Figure 1. [Figure 1 here] 
The samples were placed in $80 \mathrm{~cm}^{3}$ stainless steel cups and pyrolyzed at a cycle time of $90 \mathrm{~s}$. The pyrolysis reactions were completed in less than 30 $\mathrm{s}$ in the considered temperature range. The vapors were swept with helium gas at a flow rate of $15 \mathrm{~cm}^{3} / \mathrm{s}$ in order to ensure an inert environment for pyrolysis processes. A small sample of the product stream was extracted by the MBMS device through an orifice, where a nearly isentropic expansion occurred. The rapid cooling of the product stream due to expansion helps to eliminate the secondary cracking reactions. Next, the gases and vapors passed through a three-stage vacuum system $(\mathrm{p}=13 \mathrm{~Pa}, 100 \mathrm{mPa}$ and 100 $\mu \mathrm{Pa})$, where they were accelerated. The supersonic molecular beam was then ionized with a low-energy $(17.0 \mathrm{eV})$ electron beam. The ions were quantified with an electron multiplier detector. The pyrolysis vapors mass spectra were recorded with an Extrel mass spectrometer at a frequency of $500 \mathrm{mHz}$. Each sample was analyzed in replicate. The MBMS was chosen for the experiments due to the following advantages: i) collisionless flow, ii) preserved reactive species (low temperature), iii) ability to record time-resolved processes, and iv) quick data collection. However, MBMS data analysis can be challenging due to the uncertainty about the parent compounds of the detected fragment ions. Other factors which might influence the MBMS data are the electron energy, quadrupole tuning, and so called "mass separation" [30].

The experimental data from a fluidized bed reactor at NREL [31] were used for the purpose of validation of the modified cellulose pyrolysis mechanism. The reactor system is presented in Figure 2. [Figure 2 here] Biomass was supplied to the reactor through a feed hopper with a screw conveyor. Nitrogen gas was added in the feed system for pneumatic transport of biomass. 
Additional 5 SLM of nitrogen were supplied to the reactor to ensure proper fluidization. The fluidized bed material was olivine and the reactor inventory was $400 \mathrm{~g}$. The olivine was supplied by AGSCO with a particle size distribution of 800 to $1000 \mu \mathrm{m}$ and was $48 \% \mathrm{MgO}, 41 \% \mathrm{SiO}_{2}$ and $8 \% \mathrm{Fe}_{2} \mathrm{O}_{3}$ with minor amounts of calcium, chromium, nickel and aluminum oxides. Pyrolysis experiments were performed at $500^{\circ} \mathrm{C}$ with the residence time of $0.5 \mathrm{~s}$. Pyrolysis products were directed to a cyclone followed by a $2 \mu \mathrm{m}$ hot filter, where the char was separated from the pyrolysis gases and vapors. The reactor was equipped with a two-step oil collection system. The first step was an electrostatic precipitator (ESP), where many lignin pyrolysis products and aerosols were removed from the pyrolysis vapors. This is because lignin products have higher molecular weights and higher condensation temperatures. Pyrolysis vapors were cooled before the ESP to approximately $30^{\circ} \mathrm{C}$ in an air-cooled heat exchanger. Therefore, the ESP was also a primary condenser. The second condensation step was a dry ice condenser, which was the final liquid collection step. In order to improve mass balance closure (to $>90 \%$ ), the amount of liquid collected in different condensation steps was determined by weighing the entire condenser unit before and after the experiment.

\section{Data Analysis Methodology}

The recorded MBMS data presented in Figure 3 include the total ion current (TIC) and the respective mass spectra. TIC is the sum of all ions detected during the experiment and it provides the information about the onset, progression and completion of the pyrolysis process. The mass spectra show the relative contribution of individual fragment ions to the TIC at each 
time step, thus providing the information about product composition. The units of intensity have no direct physical meaning. [Figure 3 here]

The collected MBMS data were preprocessed in MS Excel for further analysis in the UnscramblerX [32]. The preprocessing included normalizing the data with the highest intensity in the dataset and scaling by a factor of 1,000 in order to increase the numerical values for statistical calculations. Only masses between $\mathrm{m} / \mathrm{z}=30-200$ were considered for further analysis as the higher molecular weights accounted for a relatively low percentage of the product mass $(\leq 2 \%)$. A principal component analysis (PCA) was performed on the preprocessed data in order to reduce the dimensionality of the dataset and describe the statistically significant trends with a small number of lumped product classes representative of major pyrolysis products, as determined by the principal components. These principal components were determined though the following mathematical process. Firstly, a covariance matrix was computed in order to evaluate the correlation between the fragment ions. Next, the eigenvalues and eigenvectors were calculated. The eigenvectors provide information about the correlation between samples and the eigenvalues describe the strength of these correlations. The dataset was then projected on a new set of orthogonal axes (determined by the eigenvectors) so that the variance explained was maximized by the fewest number of principal components. The results were then displayed with a score plot and a loading plot. A score plot shows the calculated values of principal components for the samples and loadings typically show the grouping of clusters of samples. A loading plot shows the relative contribution of individual mass variance to each principal component. As a result, the correlated fragment 
21

ions were grouped into clusters representative of chemical compounds or compound classes. Next, the multivariate curve resolution (MCR) (described in detail in [33]) was used to deconvolute the time-resolved data into evolving concentration score profiles of principal components. These concentration profiles were subjected to kinetic tests to determine reaction rate constants and reaction orders. The data were subjected to zero ${ }^{\text {th }}$ order, first order and a fractional order $(\mathrm{n})$ kinetic tests by performing a linear fit of the following functions plotted against time:

$$
f_{0}(t)=\frac{\int_{0}^{t} c_{P C}(t) d t}{c_{o}}
$$

$$
f_{1}(t)=\ln \left(\frac{\int_{0}^{t} c_{P C}(t) d t}{c_{o}}\right)
$$

$$
f_{n}(t)=\frac{1}{1-n} \cdot\left(\frac{\int_{0}^{t} c_{P C}(t) d t}{c_{o}}\right)^{1-n}
$$

where $f_{0}(t), f_{1}(t), f_{n}(t)$ is the zero order, first order and n-th order kinetic test function respectively, $t$ is time, $c_{P C}$ is the concentration score of a principal component, and $c_{o}$ is the total amount of products, so that the nondimensional concentration score changes between zero and one. The slope of the linear fit is equal to the reaction rate constant. The initial and final data were excluded from the kinetic analysis as they were likely affected by heat transfer limitations. Although a rigorous quantification of the products was not performed in this study the time resolved intensity profiles of fragment ions provide useful information about the evolution of products and therefore can be used to evaluate the kinetics. The advantage of this method over a thermogravimetric analysis (TGA) is the fact that it is possible to evaluate the rate of formation of individual product classes. 


\section{Results and Discussion}

The recorded mass spectra show that pure cellulose gives high yields of levoglucosan $(\mathrm{m} / \mathrm{z}=162)$ represented by characteristic fragment ions $\mathrm{m} / \mathrm{z}=57$, 60, 70, 73, 98 and 144, as illustrated in Figure 3 (b). The presence of potassium causes an increased intensity of fragment ions $\mathrm{m} / \mathrm{z}=31$, 32 characteristic of hydroxyacetaldehyde, $\mathrm{m} / \mathrm{z}=85,97,126$ representing 5-hydroxymethyl furfural, $\mathrm{m} / \mathrm{z}=85$, and $\mathrm{m} / \mathrm{z}=43\left(\mathrm{C}_{2} \mathrm{H}_{2} \mathrm{O}\right)$, which could be assigned to acetyl compounds, as shown in Figure 3 (c). The relative intensity of anhydrosugars decreases with the increased potassium treatment. The general characteristics of these mass spectra are in accordance with previous studies [30, 34]. Therefore it is suspected that potassium is either inhibiting the formation of levoglucosan or catalyzing the formation of other products. The major characteristic fragment ions in the mass spectra and their possible sources are summarized in Table 3. [Table 3 here]

PCA analysis performed on the collected MBMS data in the UnscramblerX software distinguishes the aforementioned product groups, which are represented by two principal components PC1 and PC2. The two component model explains $98 \%$ of the variance in the dataset and it is determined by the UscramblerX as an optimal model for describing the dataset. Mass spectra of the two principal components, shown in Figure 4, indicate that PC1 represents anhydrosugars and PC2 represents fragmentation products promoted by potassium carbonate (hydroxyacetaldehyde, acetyl compounds and 5-hydroxymethyl furfural). [Figure 4 here]

MCR results provide the information about the changes in time resolved concentration score profiles of the two principal components (PC1 and PC2) 
in response to an increased amount of potassium in the sample. As shown in Figure 5 (a), the concentration of anhydrosugars is much higher than the concentration of the other products during the pyrolysis of untreated cellulose. Figure 5 (c) shows that the concentration of the anhydrosugars and other products are nearly equal at $0.5 \%$ of potassium treatment, and Figure 5 (d) shows that there is significantly less anhydrosugars produced relative to other products at $1 \%$ potassium treatment. In addition, the total yield of pyrolysis vapors decreases, which results in a decreased TIC. The scale in Figure 5 (c) and (d) was adjusted for the decreased concentration score. The presented results were obtained at $510^{\circ} \mathrm{C}$, however, this trend was consistent at all considered temperatures. The numerical values of the concentration scores have no direct physical meaning. However, their relative changes in response to increased potassium treatment provide valuable information about changes in product composition. [Figure 5 here]

The obtained concentration score profiles were integrated in order to determine isothermal mass loss curves. The obtained curves were next corrected for the char yield. The comparison of the isothermal mass loss curves derived through mathematical treatment of the experimental data at $510^{\circ} \mathrm{C}$ at different levels of potassium treatment is provided in Figure 6. The results show no significant changes in the mass loss curves due to the presence of potassium. Slight differences are due to the noise in the experimental data and the mathematical treatment of the dataset. [Figure 6 here]

The kinetic tests performed on the concentration score profiles of the two principal components $\mathrm{PC} 1$ and $\mathrm{PC} 2$ reveal that the reaction order is not affected by the presence of alkali metals, and all reactions are best represented 
by first order. This also indicates that the data used were free from heat transfer limitations. The activation energies for the formation of the principal components PC1 and PC2 determined from kinetic tests are shown in Figure 7. The addition of potassium strongly inhibits the formation of levoglucosan, which manifests itself in an increased activation energy of PC1. The activation energy for the formation of the other products represented with PC2 also increases, however, at a much lower rate. The increased activation energies for both reactions, result in decreased amount of condensables. [Figure 7 here] These results are consistent with the decreased oil yield from a fluidized-bed reactor reported by Scott et al., [12]. The strong inhibition of levoglucosan formation results in the increased yield of acids and aldehydes, as shown in Figure 5. The increased mass fraction of acids and aldehydes caused by potassium has previously been reported by Patwardhan et al., [35]. Higher activation energy also leads to the delay in the onset of $\mathrm{PC} 1$ formation relative to $\mathrm{PC} 2$ formation (Figure $5 \mathrm{c}$ and $\mathrm{d}$ ).

The char yield was determined by weighing the solid residue after the experiment. As shown in Figure 8, char yield increases from $3.7 \%$ of the pure cellulose sample to $14.0 \%$ of the sample treated with $1 \%$ potassium. The temperature had a negligible effect on the char yield within the considered range between $480-520^{\circ} \mathrm{C}$. The char yield data were used to determine the activation energy of the char formation reaction as a function of potassium treatment. The activation energy for the char formation was calculated by matching the predicted char yields with the experimental data.[Figure 8 here] The determined activation energies and pre-exponential factors were incorporated into the cellulose pyrolysis mechanism developed by Ranzi et al., 
[28]. The original mechanism, shown in Figure 9 (a), is comprised of four reactions. Firstly, cellulose is partially depolymerized according to reaction (R1). Next, the active cellulose (at low degree of polymerization) undergoes either depolymerization leading to levoglucosan formation (R3) or fragmentation leading to the formation of acids, aldehydes, other volatiles and char (R2). In addition to this pathway, there is a competing dehydration reaction, which leads to formation of char (cross-linking) and water (R4). [Figure 9 here] The products of the dehydration reaction usually also include gases $[27,36]$, which are missing in the presented mechanism. Therefore an additional adjustment was made in the reaction stochiometry to incorporate the produced $\mathrm{CO}, \mathrm{CO}_{2}$, and $\mathrm{H}_{2}$, as shown in Figure 9 (b). The activation energies of reactions R2, R3 and R4 were adjusted, as functions of potassium treatment based on the experimental data. The activation energies of reactions R2 and R3 increase with the increased potassium treatment, since potassium strongly inhibits levoglucosan formation (R3) and mildly inhibits the fragmentation reaction (R2). The activation energy of the dehydration reaction (R4) decreases as it is catalyzed by potassium. The activation energies and pre-exponents of reactions R2, R3 and R4 for pure cellulose are summarized in Table 4. [Table 4 here]The adjusted activation energies are in the same order of magnitude compared with the original mechanism. The general trends are similar; the activation energy of transglycosylation is lower than the activation energy for fragmentation and for char formation; however it is noteworthy that the activation energy of transglycosylation approaches that of fragmentation. Moreover, the proposed activation energies are in a reasonable agreement with the values reported by Diebold [37]. However, 
a direct comparison of the activation energies derived in this study with other values reported in the literature might not be justified as those activation energies describe different reaction pathways. In addition, the activation energies might vary due to the different experimental equipment, inability to accurately determine the sample temperature during experiments, heat and mass transfer limitations, compositional and size differences of biomass samples or mathematical treatment of experimental data. The adaptation of the pyrolysis mechanism proposed in this study is different from the approach presented by Anca-Couce et al. [29]. This is because in this study, the particle size was very small $(50 \mu \mathrm{m})$ and the product vapors were immediately removed from the pyrolyzer. Therefore, the authors think that it is unlikely that secondary reactions were the dominant mechanism of char formation in this study. Moreover, the char yield was determined by weighing the residue after pyrolysis. The activation energy for charring reaction was adjusted based on the collected yield data. Therefore, the available information was not detailed enough to propose appropriate secondary reactions and evaluate the respective kinetic parameters. The authors do not claim that the proposed mechanism is the only possible explanation of the effect of potassium. It might be desired to extend the model and incorporate secondary reactions in the future. However, the proposed approach seems reasonable to the authors based on the collected data.

Since the activation energies of reactions R2, R3, R4 change as functions of the potassium treatment $(\% \mathrm{~K})$, the following functions describing these change were obtained by fitting the experimental data presented in Figure 7 
and $8(b)$ :

$$
\begin{aligned}
& E_{a, 2}(\% K)=100.16 x^{0.0168} \\
& E_{a, 3}(\% K)=118.99 x^{0.056} \\
& E_{a, 4}(\% K)=124.52 x^{-0.03}
\end{aligned}
$$

where $E_{a}$ is the activation energy $(\mathrm{kJ} / \mathrm{mol})$, and $\mathrm{x}$ is the mass fraction of potassium (\%).

The modified cellulose pyrolysis mechanism was implemented in gPROMS software [38]. Simulations were performed under isothermal conditions at $500^{\circ} \mathrm{C}$ and the residence time of $0.5 \mathrm{~s}$ in order to investigate the effect of potassium on cellulose pyrolysis products in more details. Simulation results show that the increased potassium treatment causes a dramatic reduction in the oil yield from $87.9 \%$ from untreated avicel to $54.0 \%$ at $0.5 \%$ potassium treatment. Further increase in potassium treatment causes a further decrease in the oil yield to $46.2 \%$ at $1 \%$ potassium treatment. The decrease of the oil yield is accompanied by an increase of the gas and char yield. The predicted char yield increases from $3.7 \%$ from pure avicel to $14.0 \%$ at $1 \%$ potassium treatment and the gas yield increases from $8.4 \%$ from pure avicel to $39.8 \%$ at $1 \%$ potassium treatment, as shown in Figure 10 (a). [Figure 10 here]

The composition of the produced pyrolysis oil is also altered in the presence of potassium. The predicted levoglucosan weight fraction decreases dramatically from $48.8 \%$ of the produced oil from pure cellulose to only $5.6 \%$ of the oil at $0.5 \%$ potassium treatment, as shown in Figure 10 (b). Further increase in the potassium treatment causes further decrease in the levoglucosan yield to $3.1 \%$ at $1 \%$ potassium treatment. Increasing the level of potassium treatment is expected to eventually lead to zero levoglucosan yield. 
The large initial drop of the predicted levoglucosan yield supports the theory that potassium inhibits the unzipping reactions of cellulose molecules. The inhibition of levoglucosan formation results in the increased yields of acids and aldehydes produced in the competing fragmentation reaction. Moreover, the heating value of the produced oil decreases with the increased potassium treatment due to increased predicted weight fraction of water from $6.1 \%$ of the oil from pure cellulose to $21.9 \%$ of the oil at $1 \%$ potassium treatment. The increased water yield is due to both decreased yield of organics and additional water produced in the catalyzed dehydration reaction.

The simulation results were validated with the experimental data obtained from the fluidized-bed reactor [31]. The experiments in the fluidized bed reactor were performed with avicel and $0.1 \%$ potassium treated avicel. Experimentally the addition of potassium caused a reduction of oil yield from $86.9 \%$ to $68.8 \%$, an increase of gas yield from $13.0 \%$ to $22.9 \%$, and an increase of char yield from $0.1 \%$ to $8.3 \%$. The comparison of the experimental data with model results is given in Table 5 . [Table 5 here] The model results are in excellent agreement with the experimental yields, with the differences in yields below $5 \%$ points. This is a very good result, given the uncertainty related to the experimental data. The standard deviation in the oil yield from the fluidized bed reactor was $7.1 \%$ points. The mass balance closure in the pure avicel experiment and the potassium treated avicel experiment was $94.9 \%$ and $90.4 \%$ respectively. The mass imbalance was related to the oil collection system and it was added to the oil yield in Table 5. The lower than expected experimental char yield is not completely unexpected since the experimental fluidized-bed reactor is susceptible to errors in the char 
collection system.

\section{Conclusions}

An adjusted cellulose pyrolysis mechanism was proposed to account for the effect of potassium, which causes severe reduction of oil yield and has an adverse effect on the oil composition. The simulation results reveal that potassium strongly inhibits levoglucosan formation and promotes the formation of char, water and gases. As a result the predicted oil yield decreases from $87.9 \%$ achieved with pure avicel to $54.0 \%$ at $0.5 \%$ potassium treatment, the predicted char yield increases from 3.7\% to $12.1 \%$ and the predicted gas yield increases from $8.4 \%$ to $33.9 \%$. Moreover, the heating value of the produced oil decreases because of the increased predicted weight fraction of water from $6.1 \%$ to $18.1 \%$. The simulation results were in good agreement with the experimental data from a fluidized-bed reactor. The differences in product yields were below $5 \%$ on an absolute yield basis. This suggests that the underlying model with the proposed adjustments may be extended to derive practical value for predicting fast pyrolysis products in biorefinery plant simulations, especially when there are variations in ash in the supplied feedstock.

\section{Acknowledgements}

We thank the U.S. Department of Energy's Bioenergy Technologies Office (DOE-BETO) for supporting this work under Contract No. DE-AC36-08GO28308 with the National Renewable Energy Laboratory. 


\section{References}

[1] Ringer M, Putsche V, Scahill J. Large-Scale Pyrolysis Oil Production: A Technology Assessment and Economic Analysis, Technical Report NREL/TP-510-37779. 2006;P-510-37779.

[2] Wright MM, Daugaard DE, Satrio JA, Brown RC. Techno-economic analysis of biomass fast pyrolysis to transportation fuels, Technical Report NREL/TP-6A20-46586. 2010;.

[3] Jones S, Meyer P, Snowden-Swan A, Padmaperuma, Tan E, Dutta A, et al. Process Design and Economics for the Conversion of Lignocellulosic Biomass to Hydrocarbon Fuels, Fast Pyrolysis and Hydrotreating Bio-oil Pathway, Technical Report PNNL-23053, NREL/TP-510061178. 2013;

[4] Kersten SR, Wang X, Prins W, van Swaaij WP. Biomass pyrolysis in a fluidized bed reactor. Part 1: Literature review and model simulations. Industrial \& engineering chemistry research. 2005;44(23):8773-8785.

[5] Van de Velden M, Baeyens J, Boukis I. Modeling CFB biomass pyrolysis reactors. Biomass and Bioenergy. 2008;32(2):128-139.

[6] Kaushal P, Abedi J. A simplified model for biomass pyrolysis in a fluidized bed reactor. Journal of Industrial and Engineering Chemistry. 2010;16(5):748-755.

[7] Mellin P, Kantarelis E, Yang W. Computational fluid dynamics modeling of biomass fast pyrolysis in a fluidized bed reactor, using a comprehensive chemistry scheme. Fuel. 2014;117:704-715. 
[8] Trendewicz A, Braun R, Dutta A, Ziegler J. One dimensional steadystate circulating fluidized-bed reactor model for biomass fast pyrolysis. Fuel. 2014;133:253-262.

[9] Patwardhan PR. Understanding the product distribution from biomass fast pyrolysis. PhD Thesis at Iowa State University. 2010;.

[10] Olsson JG, Jäglid U, Pettersson JB, Hald P. Alkali metal emission during pyrolysis of biomass. Energy \& Fuels. 1997;11(4):779-784.

[11] Vassilev SV, Baxter D, Andersen LK, Vassileva CG. An overview of the composition and application of biomass ash. Part 1. Phase-mineral and chemical composition and classification. Fuel. 2013;105:40-76.

[12] Scott DS, Piskorz J, Radlein D. Liquid products from the continuous flash pyrolysis of biomass. Industrial \& Engineering Chemistry Process Design and Development. 1985;24(3):581-588.

[13] Varhegyi G, Antal Jr MJ, Szekely T, Till F, Jakab E. Simultaneous thermogravimetric-mass spectrometric studies of the thermal decomposition of biopolymers. 1. Avicel cellulose in the presence and absence of catalysts. Energy \& fuels. 1988;2(3):267-272.

[14] Pan WP, Richards GN. Influence of metal ions on volatile products of pyrolysis of wood. Journal of Analytical and Applied Pyrolysis. 1989;16(2):117-126.

[15] Williams PT, Horne PA. The role of metal salts in the pyrolysis of biomass. Renewable Energy. 1994;4(1):1-13. 
[16] Antal MJJ, Varhegyi G. Cellulose pyrolysis kinetics: the current state of knowledge. Industrial \& Engineering Chemistry Research. 1995;34(3):703-717.

[17] Shimada N, Kawamoto H, Saka S. Different action of alkali/alkaline earth metal chlorides on cellulose pyrolysis. Journal of Analytical and Applied Pyrolysis. 2008;81(1):80-87.

[18] Shafizadeh F. Pyrolysis and combustion of cellulosic materials. Advances in carbohydrate chemistry. 1968;23:419-474.

[19] Antal Jr MJ. Biomass pyrolysis: a review of the literature part 1 carbohydrate pyrolysis. In: Advances in solar energy. Springer; 1985. p. $61-111$.

[20] Madorsky S, Hart V, Straus S. Thermal Degradation of Cellulosic Materials. Journal of Research of the National Bureau of Standards. 1958;60(4):343-349.

[21] Fung D, Tsuchiya Y, Sumi K. Thermal degradation of cellulose and levoglucosan: the effect of inorganic stalts. Wood Science. 1972;5(1):3843.

[22] Piskorz J, Radlein DSA, Scott DS, Czernik S. Pretreatment of wood and cellulose for production of sugars by fast pyrolysis. Journal of Analytical and Applied Pyrolysis. 1989;16(2):127-142.

[23] Kawamoto H, Morisaki H, Saka S. Secondary decomposition of levoglucosan in pyrolytic production from cellulosic biomass. Journal of Analytical and Applied Pyrolysis. 2009;85(1):247-251. 
[24] Kawamoto H, Murayama M, Saka S. Pyrolysis behavior of levoglucosan as an intermediate in cellulose pyrolysis: polymerization into polysaccharide as a key reaction to carbonized product formation. Journal of Wood Science. 2003;49(5):469-473.

[25] Hosoya T, Kawamoto H, Saka S. Different pyrolytic pathways of levoglucosan in vapor-and liquid/solid-phases. Journal of Analytical and Applied Pyrolysis. 2008;83(1):64-70.

[26] Miller R, Bellan J. A generalized biomass pyrolysis model based on superimposed cellulose, hemicelluloseand liqnin kinetics. Combustion Science and Technology. 1997;126(1-6):97-137.

[27] Di Blasi C. Modeling chemical and physical processes of wood and biomass pyrolysis. Progress in Energy and Combustion Science. 2008;34(1):47-90.

[28] Ranzi E, Corbetta M, Manenti F, Pierucci S. Kinetic modeling of the thermal degradation and combustion of biomass. Chemical Engineering Science. 2014;110:2-12.

[29] Anca-Couce A, Mehrabian R, Scharler R, Obernberger I. Kinetic scheme of biomass pyrolysis considering secondary charring reactions. Energy Conversion and Management. 2014;87:687-696.

[30] Evans RJ, Milne TA. Molecular characterization of the pyrolysis of biomass. 1. Fundamentals. Energy \& Fuels. 1987;1(2):123-137.

[31] Schlichting G. Thermochemical conversion of biomass to hydrogen 
via fast pyrolysis and catalytic reforming. Feedstock variability for distributed reforming. Master's Thesis at Colorado School of Mines, Department of Chemical Engineering. 2009;.

[32] The UnscramblerX 10.3. CAMO Software. 2013;

[33] Ruckebusch C, Blanchet L. Multivariate curve resolution: A review of advanced and tailored applications and challenges. Analytica Chimica Acta. 2013;765(0):28 - 36.

[34] Evans RJ, Wang D, Agblevor FA, Chum HL, Baldwin SD. Mass spectrometric studies of the thermal decomposition of carbohydrates using 13 C-labeled cellulose and glucose. Carbohydrate research. 1996;281(2):219-235.

[35] Patwardhan PR, Satrio JA, Brown RC, Shanks BH. Influence of inorganic salts on the primary pyrolysis products of cellulose. Bioresource technology. 2010;101(12):4646-4655.

[36] Van de Velden M, Baeyens J, Brems A, Janssens B, Dewil R. Fundamentals, kinetics and endothermicity of the biomass pyrolysis reaction. Renewable energy. 2010;35(1):232-242.

[37] Diebold JP. A unified, global model for the pyrolysis of cellulose. Biomass and Bioenergy. 1994;7(1):75-85.

[38] Release 2012; ModelBuilder3.6.0.54865, Process Systems Enterprise Ltd; 


\section{List of Figures}

Figure 1. Experimental set-up schematic showing a pyrolyzer with the autosampler connected to the MBMS

Figure 2. Schematic of an experimental fluidized bed reactor system at NREL Figure 3. Recorded MBMS data a) total ion current (TIC) b) mass spectra of cellulose pyrolysis products, c) mass spectra of pyrolysis products of cellulose treated with $1 \%$ potassium at $510^{\circ} \mathrm{C}$

Figure 4. Mass spectra of principal components a) PC1, b) PC2

Figure 5. Concentration profiles of principal components PC1 and PC2 at $510^{\circ} \mathrm{C}$ a) pure cellulose, b) $0.05 \%$ potassium treatment, c) $0.5 \%$ potassium treatment, d) $1 \%$ potassium treatment

Figure 6. Comparison of the mass loss curves mathematically derived from experimental data at $510^{\circ} \mathrm{C}$ at different levels of potassium treatment

Figure 7. The effect of potassium treatment on activation energies for the formation of principal components $\mathrm{PC} 1$ and $\mathrm{PC} 2$

Figure 8. The effect of potassium treatment on a) char yield, b) activation energy of char formation

Figure 9. The schematic of the cellulose pyrolysis reaction mechanism a) original mechanism [28], b) mechanism with adjustments for the effect of potassium

Figure 10. The effect of potassium treatment on a) product yield, b) oil composition from fast pyrolysis of cellulose at $500^{\circ} \mathrm{C}$ and $0.5 \mathrm{~s}$ residence time 


\section{List of Tables}

565 Table 1. Elemental analysis of ash (mass fractions) obtained from pine, 566 switchgrass and oak at NREL

${ }_{567}$ Table 2. Summary of the research findings on the catalytic effect of alkali 568 metals on cellulose pyrolysis reaction mechanism

${ }_{569}$ Table 3. Major characteristic fragment ions in cellulose pyrolysis product 570 mass spectra and their possible sources

${ }_{571}$ Table 4. Activation energies and pre-exponents of reactions R2, R3, R4 for 572 pure cellulose

573 Table 5. Comparison of avicel and potassium treated avicel pyrolysis product 574 yields from model prediction with experimental data

575 


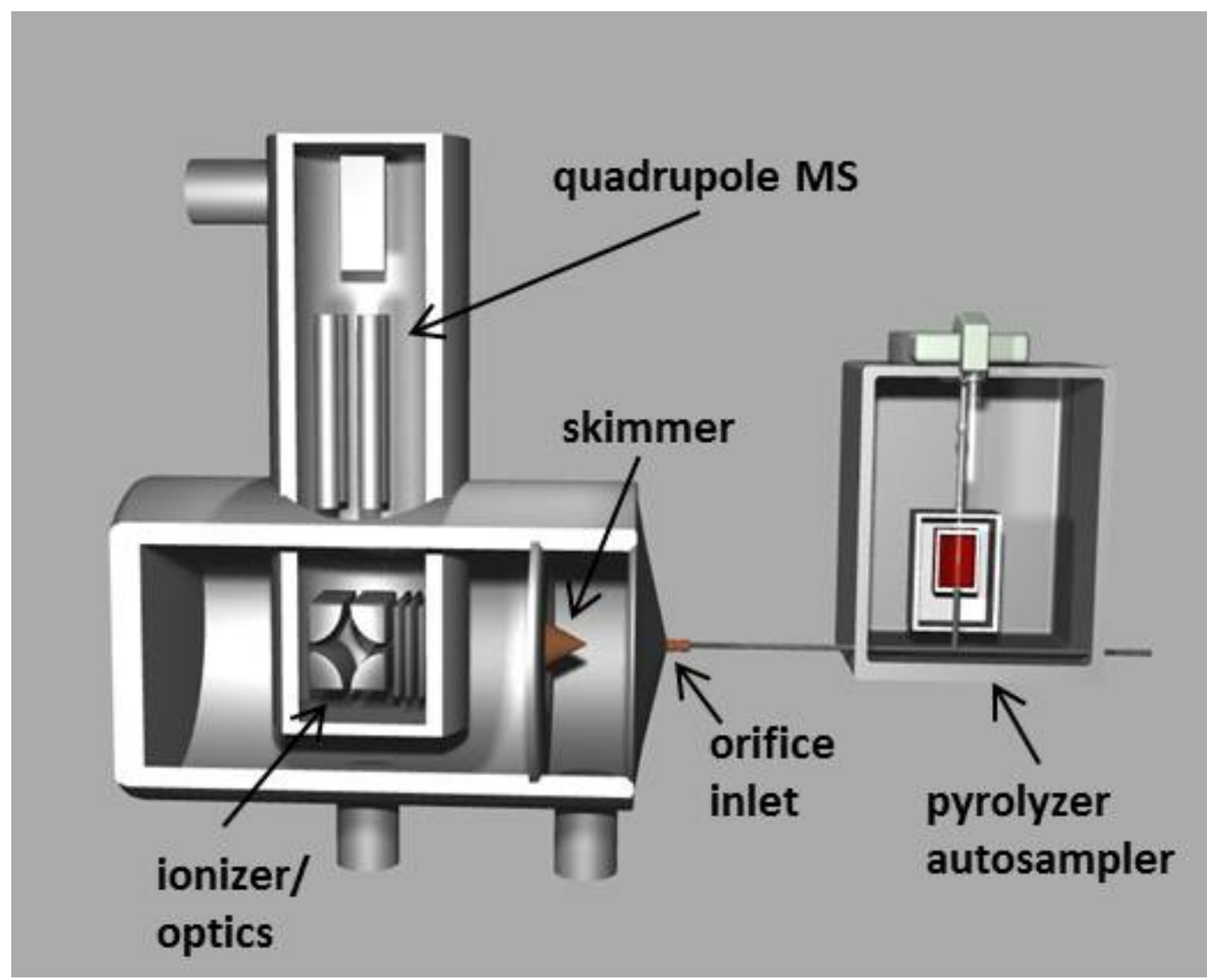

Figure 1: Experimental set-up schematic showing a pyrolyzer with the autosampler connected to the MBMS 


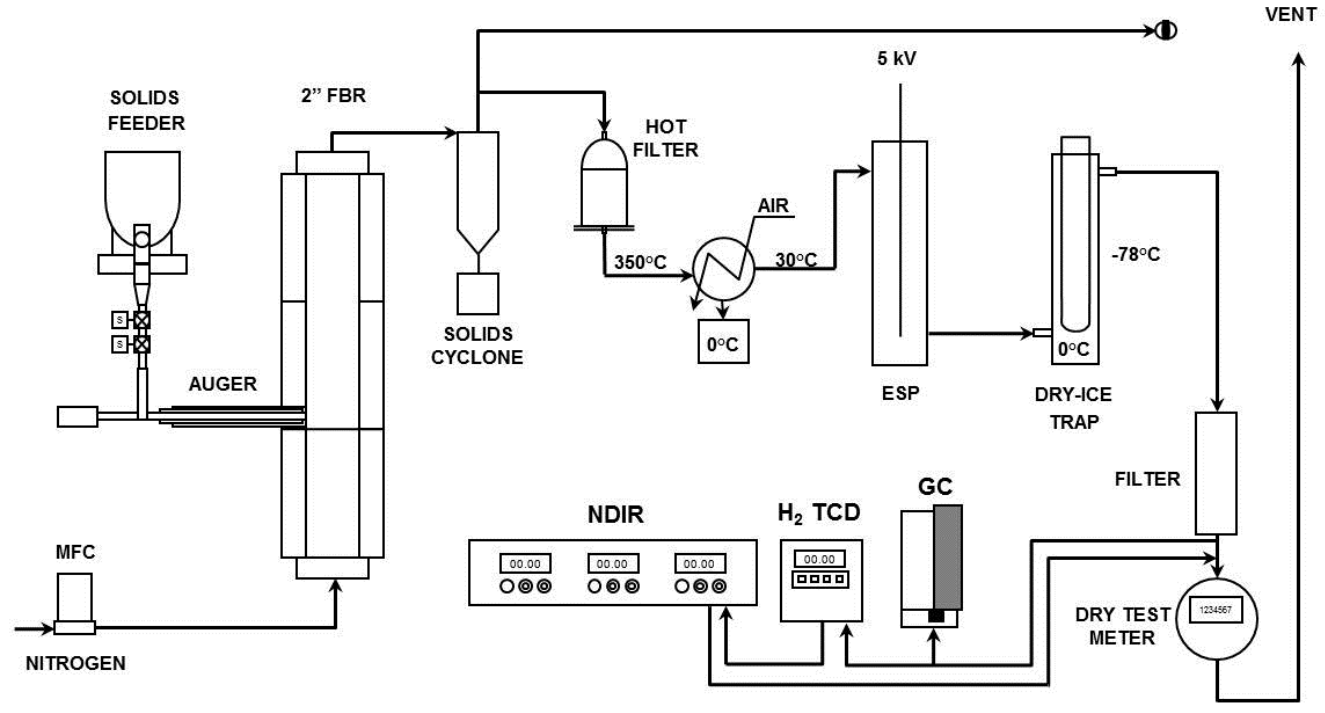

Figure 2: Schematic of an experimental fluidized bed reactor system at NREL 

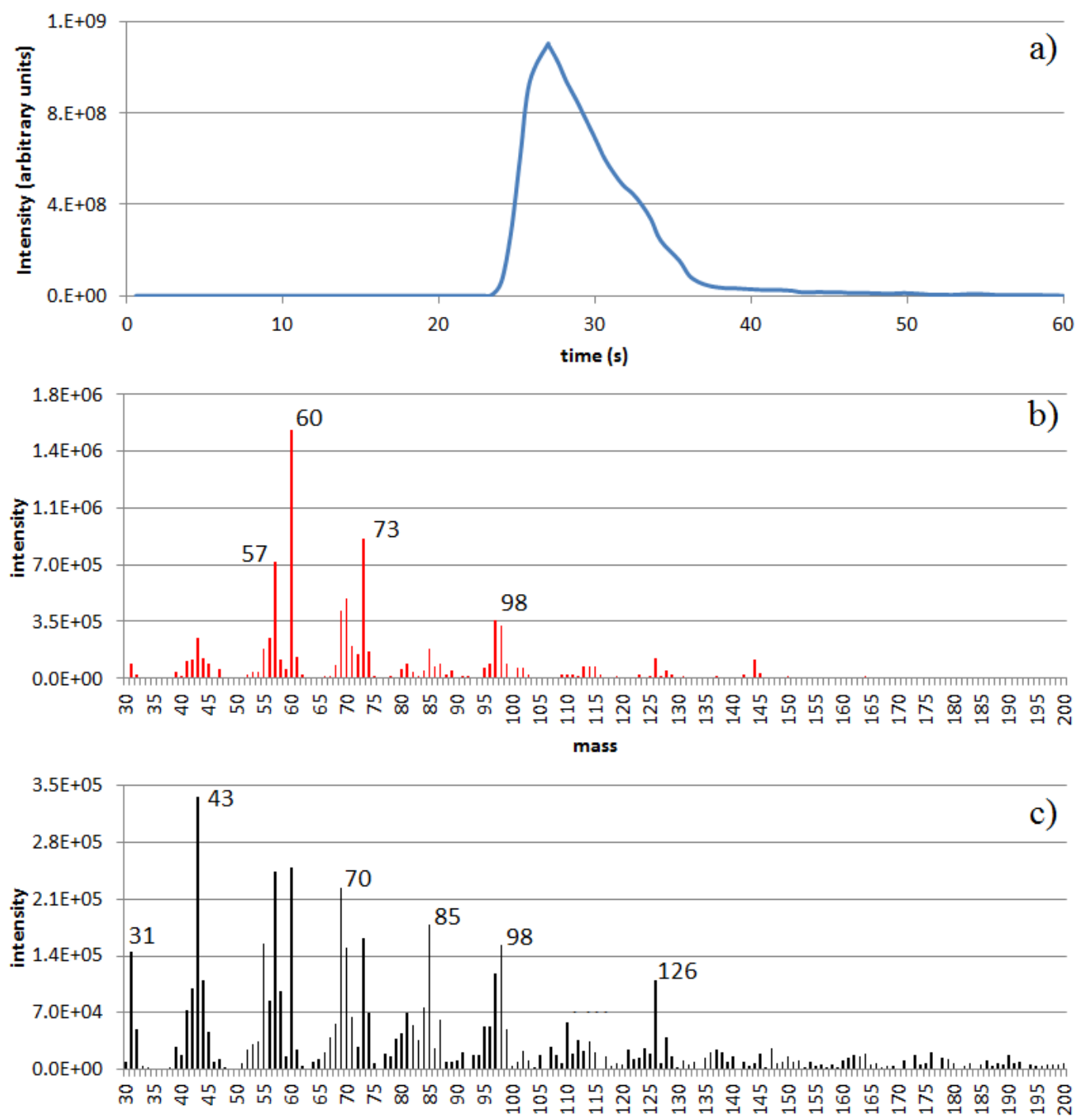

mass

Figure 3: Recorded MBMS data a) total ion current (TIC) b) mass spectra of cellulose pyrolysis products, c) mass spectra of pyrolysis products of cellulose treated with $1 \%$ potassium at $510^{\circ} \mathrm{C}$ 

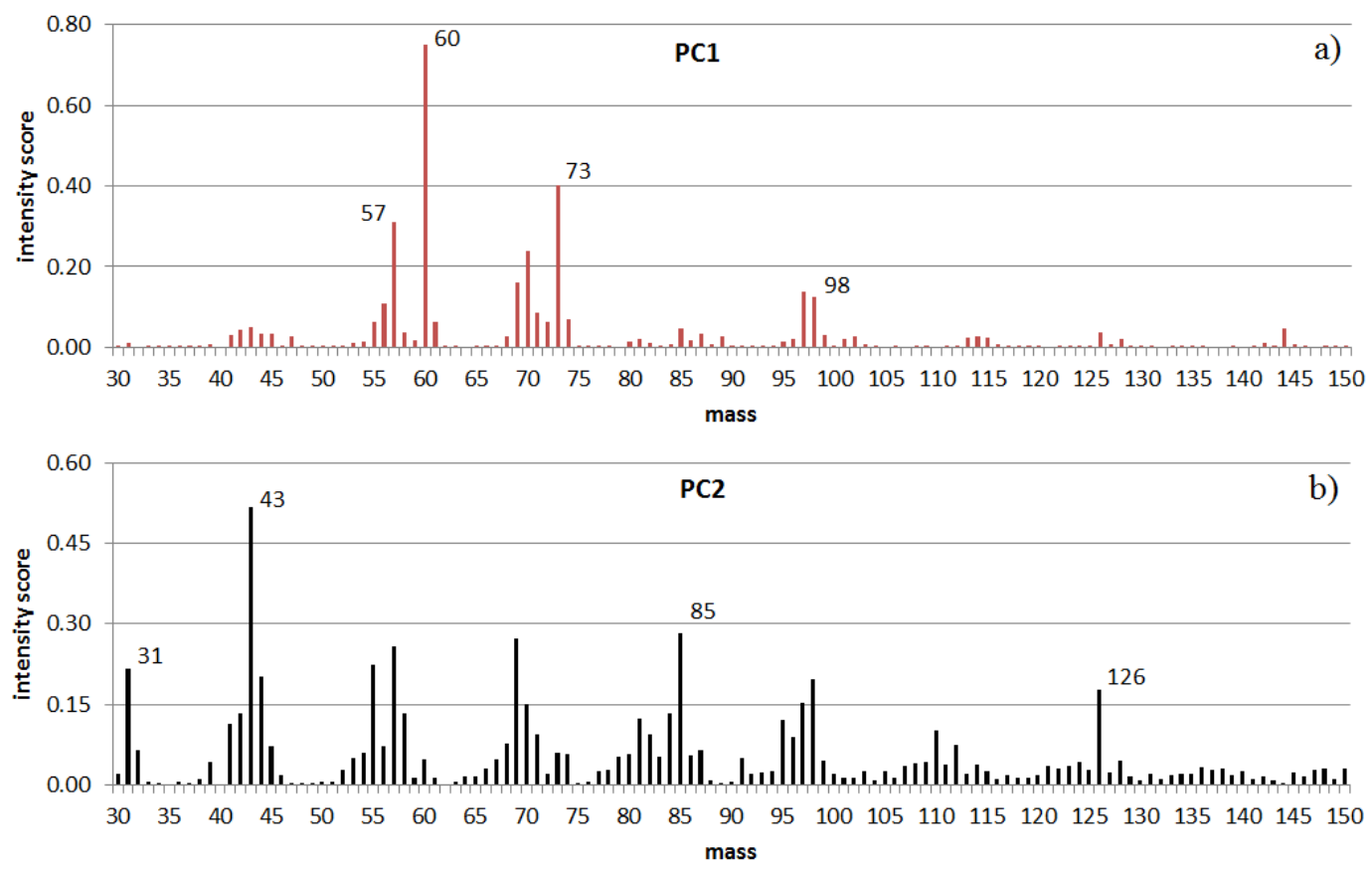

Figure 4: Mass spectra of principal components a) PC1, b) PC2 

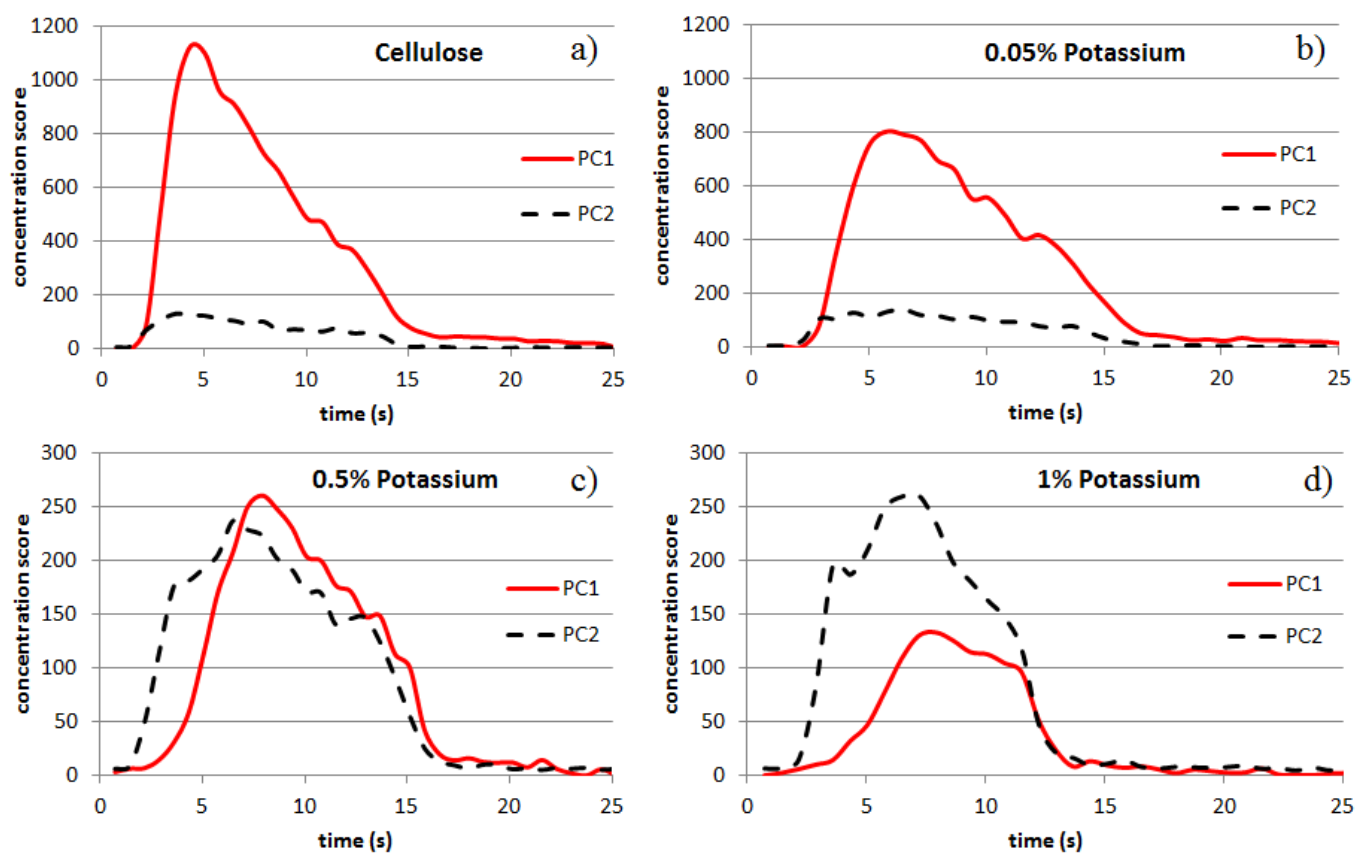

Figure 5: Concentration profiles of principal components $\mathrm{PC} 1$ and $\mathrm{PC} 2$ at $510^{\circ} \mathrm{C}$ a) pure cellulose, b) $0.05 \%$ potassium treatment, c) $0.5 \%$ potassium treatment, d) $1 \%$ potassium treatment 


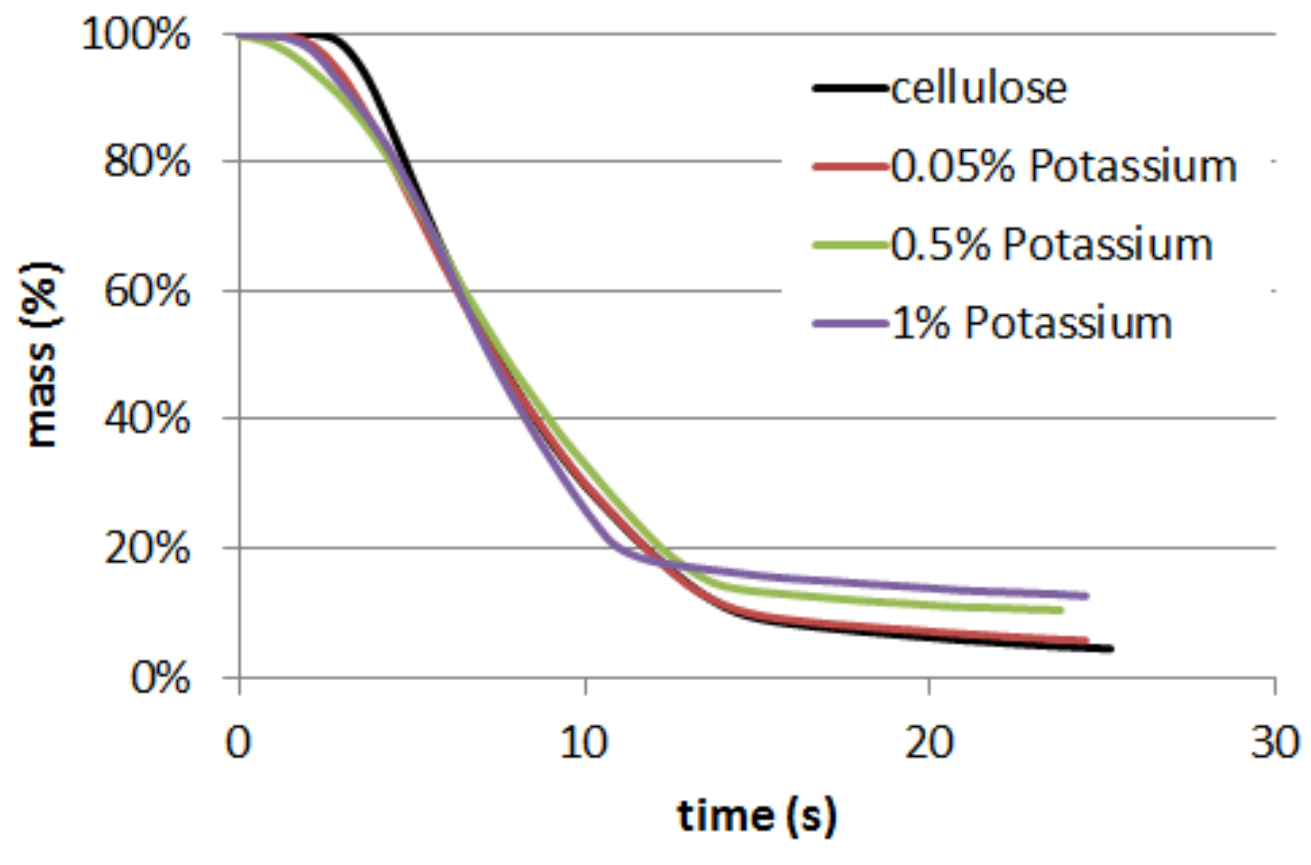

Figure 6: Comparison of the mass loss curves mathematically derived from experimental data at $510^{\circ} \mathrm{C}$ at different levels of potassium treatment 


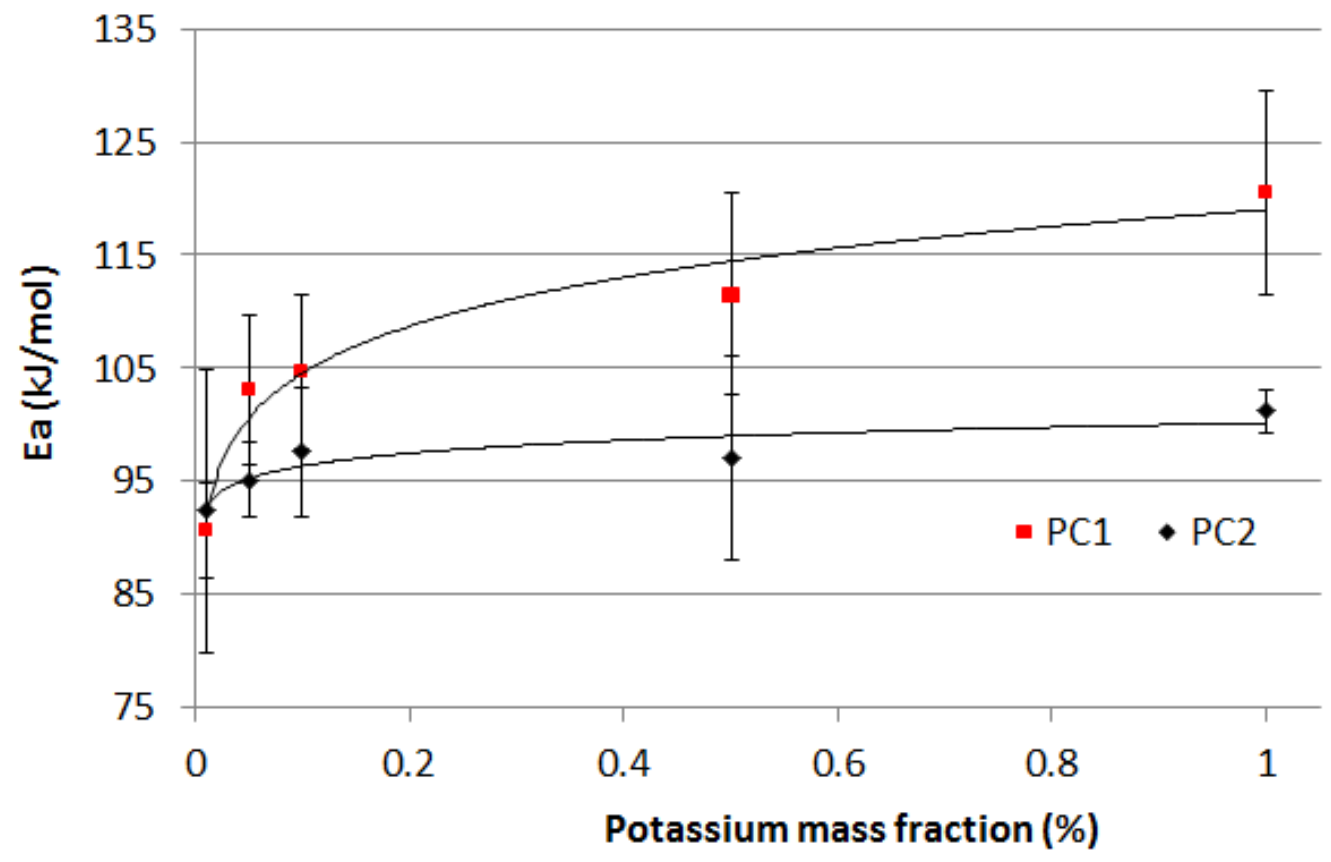

Figure 7: Activation energies for the formation of principal components PC1 and PC2 as a function of the level of potassium treatment 

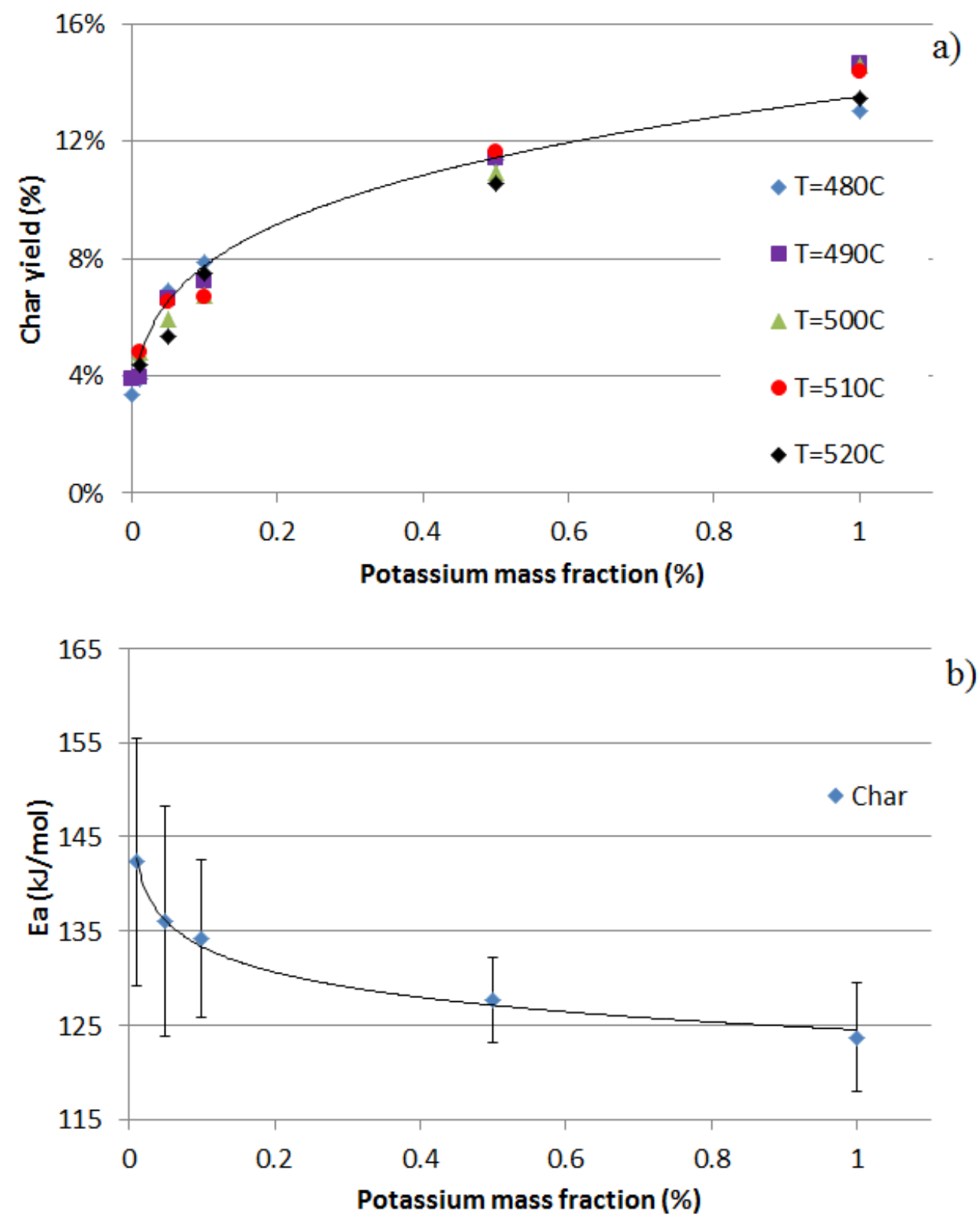

Figure 8: The effect of potassium treatment on a) char yield, b) activation energy of char formation 
a)

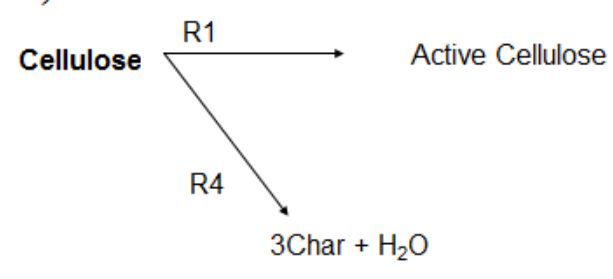

b)

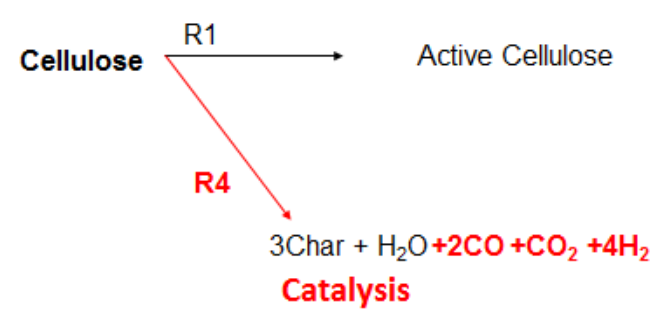

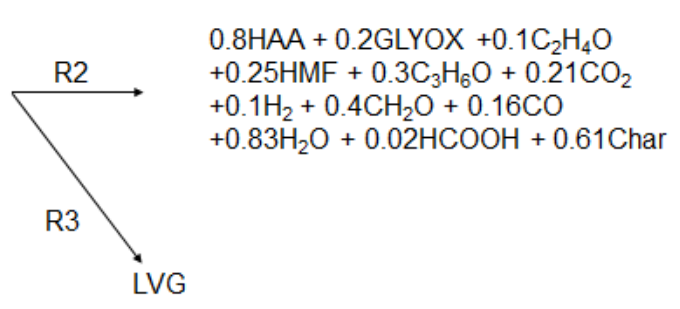

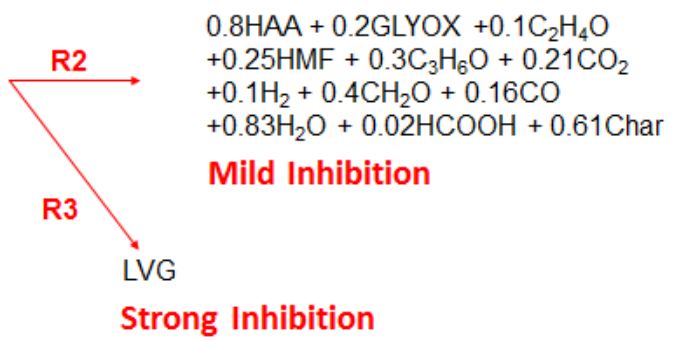

Figure 9: The schematic of the cellulose pyrolysis reaction mechanism a) original mechanism [28], b) mechanism with adjustments for the effect of potassium 

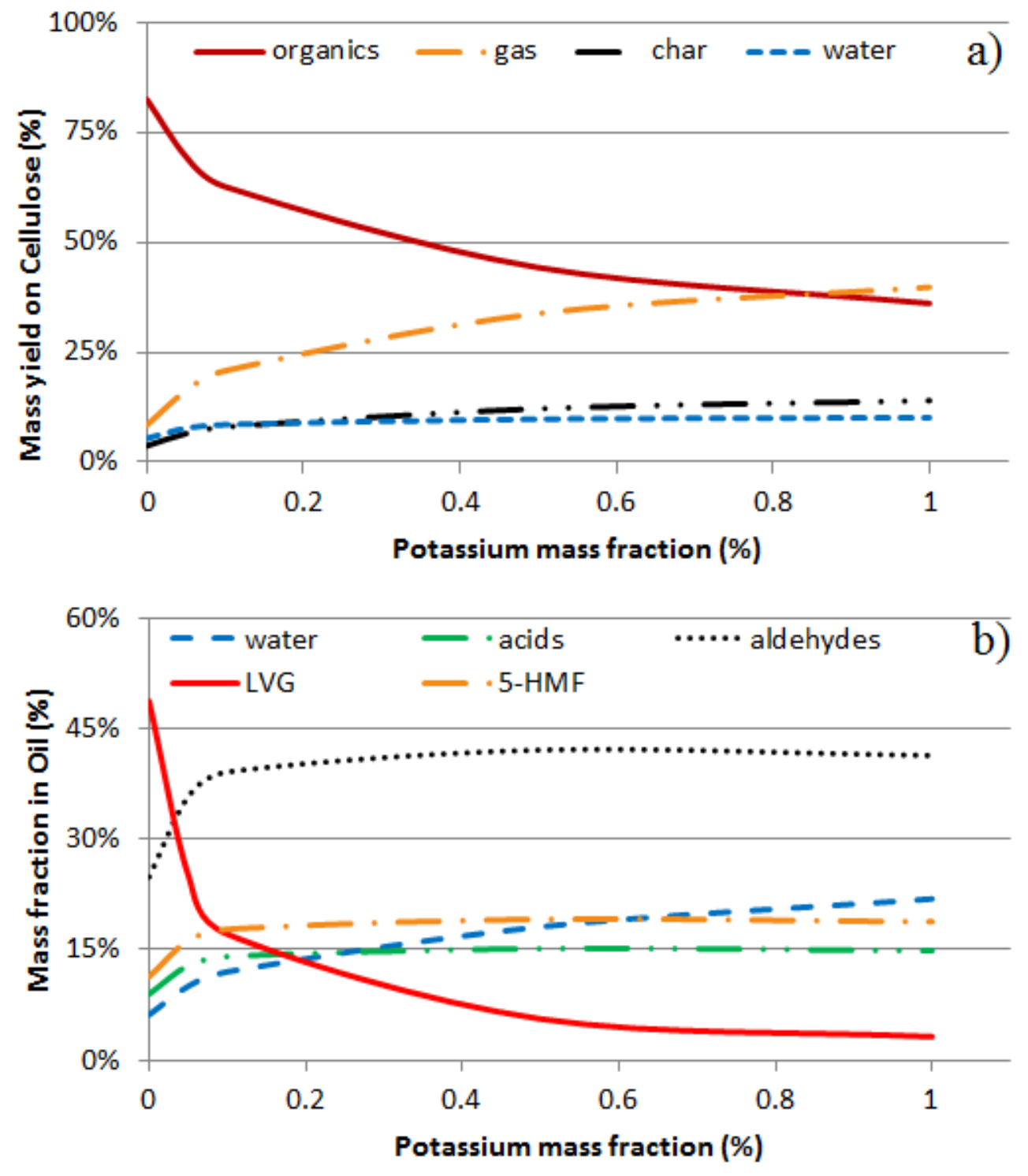

Figure 10: Prediction of the effect of potassium treatment on a) product yield, b) oil composition from fast pyrolysis of cellulose at $500^{\circ} \mathrm{C}$ and $0.5 \mathrm{~s}$ residence time 
Table 1: Composition of ash (mass fractions) obtained from pine, switchgrass and oak at NREL

\begin{tabular}{cccc}
\hline Feedstock & Pine & Switchgrass & Oak \\
\hline Ash $(\%)$ & 0.44 & 6.02 & 0.27 \\
\hline $\mathrm{SiO}_{2}(\%)$ & 39.88 & 64.96 & 4.78 \\
$\mathrm{Al}_{2} \mathrm{O}_{3}(\%)$ & 3.87 & 3.28 & 2.15 \\
$\mathrm{TiO}_{2}(\%)$ & $<0.01$ & 0.13 & $<0.01$ \\
$\mathrm{Fe}_{2} \mathrm{O}_{3}(\%)$ & 2.70 & 1.01 & 0.81 \\
$\mathrm{CaO}(\%)$ & 21.60 & 9.35 & 32.40 \\
$\mathrm{MgO} \%)$ & 5.08 & 2.03 & 1.54 \\
$\mathrm{Na}_{2} \mathrm{O}(\%)$ & 1.58 & 0.52 & 0.71 \\
$\mathrm{~K}_{2} \mathrm{O}(\%)$ & 12.10 & 7.21 & 20.40 \\
$\mathrm{P}_{2} \mathrm{O}_{5}(\%)$ & 3.36 & 4.46 & 2.12 \\
$\mathrm{SO}_{3}(\%)$ & 1.56 & 0.77 & 0.79 \\
$\mathrm{Cl}_{(\%)}$ & 0.31 & 3.28 & 2.15 \\
$\mathrm{CO}_{2}(\%)$ & 9.24 & 0.91 & 32.48 \\
\hline
\end{tabular}


Table 2: Summary of the research findings on the catalytic effect of alkali metals on cellulose pyrolysis reaction mechanism

Research Paper Proposed Catalytic Effect on Reaction Mechanism

Madorsky et al. neutral salts suppress levoglucosan formation and promote char for$[20]$ mation

Shafizadeh [18], acid catalysts promote the formation of glucosenone, furan derivaAntal [19] tives and char; alkaline catalysts promote the formation of glyoxal, acetaldehyde, low molecular weight carbonyl compounds and char

Fung et al. [21] acid, alkaline and neutral salts inhibit the formation of levoglucosan

Evans et al. [30] alkali metals inhibit the formation of levoglucosan by disrupting the transglycosylation, they promote the formation of carbonyl groups, double bonds and substituted furans

Piskorz et al. alkali metals suppress levoglucosan formation by capping the free ends of cellulose chains and inhibiting the unzipping reaction; they promote the formation of glycolaldehyde via the alternative pathway

Williams and the catalytic effect of alkali metals is likely through ionic catalysis

Horne [15] with a negligible impact of the acidity, alkalinity or neutrality of the salts

Kawamoto et al. levoglucosan undergoes secondary reactions through either frag$[24,23,25]$ mentation or polymerization, the reactions can occur also in liquid phase

Patwardhan et inorganic salts/ash promote the formation of formic acid, glycoal. [35] laldehyde and acetol; they suppress the competing reaction leading to levoglucosan formation 
Table 3: Major characteristic fragment ions in cellulose pyrolysis product mass spectra and their possible sources

\begin{tabular}{lll}
\hline Ion $(\mathrm{m} / \mathrm{z})$ & $\mathrm{Chemical} \mathrm{Formula}$ & Possible Source \\
\hline 31 & $\mathrm{CH}_{3} \mathrm{O}$ & hydroxyacetaldehyde \\
43 & $\mathrm{CH}_{4} \mathrm{O}$ & hydroxyacetaldehyde \\
57 & $\mathrm{C}_{2} \mathrm{H}_{3} \mathrm{O}$ & acetyl \\
60 & $\mathrm{C}_{2} \mathrm{HO}_{2}, \mathrm{C}_{3} \mathrm{H}_{5} \mathrm{O}$ & levoglucosan \\
& $\mathrm{C}_{2} \mathrm{H}_{4} \mathrm{O}_{2}$ & levoglucosan, acetic acid, \\
70 & & hydroxyacetaldehyde \\
73 & $\mathrm{C}_{4} \mathrm{H}_{6} \mathrm{O}$ & levoglucosan \\
85 & $\mathrm{C}_{3} \mathrm{H}_{5} \mathrm{O}_{2}$ & levoglucosan \\
& $\mathrm{C}_{4} \mathrm{H}_{5} \mathrm{O}_{2}$ & 5-hydroxymethylfurfural, \\
97 & & pentosan \\
98 & $\mathrm{C}_{5} \mathrm{H}_{4} \mathrm{O}_{2}$ & 5-hydroxymethylfurfural \\
& $\mathrm{C}_{5} \mathrm{H}_{6} \mathrm{O}_{2}$ & levoglucosan, furfuryl alco- \\
110 & & hol \\
& $\mathrm{C}_{6} \mathrm{H}_{6} \mathrm{O}_{2}$ & 5-hydroxymethylfurfural, \\
& & catechol, resorcinol \\
126 & $\mathrm{C}_{6} \mathrm{H}_{6} \mathrm{O}_{3}$ & 5-hydroxymethylfurfural, \\
& & trihydroxybenzene, levoglu- \\
& $\mathrm{C}_{6} \mathrm{H}_{8} \mathrm{O}_{3}$ & cosenone \\
& & levoglucosan \\
\hline
\end{tabular}


Table 4: Activation energies and pre-exponents of reactions R2, R3, R4 for pure cellulose

\begin{tabular}{lcc}
\hline Reaction & Activation Energy $(\mathrm{kJ} / \mathrm{mol})$ & Pre-exponent $(1 / \mathrm{s})$ \\
\hline R2 & $93.6 \pm 9.6$ & $3.78 \cdot 10^{9}$ \\
R3 & $90.8 \pm 0.8$ & $2.61 \cdot 10^{9}$ \\
R4 & $142.3 \pm 2.1$ & $2.00 \cdot 10^{9}$ \\
\hline
\end{tabular}

Table 5: Comparison of avicel and potassium treated avicel pyrolysis product yields from model prediction with experimental data

\begin{tabular}{lcc}
\hline Product Yield & Avicel & Avicel $+0.1 \% \mathrm{~K}$ \\
& (Simulation/Experiment) & (Simulation/Experiment) \\
\hline Oil $(\%)$ & $87.9 / 86.9$ & $71.2 / 68.6$ \\
Char $(\%)$ & $3.7 / 0.1$ & $8.0 / 8.3$ \\
Gas $(\%)$ & $8.4 / 13.0$ & $20.8 / 22.9$ \\
\hline
\end{tabular}

